\title{
Dose de máxima eficiência técnica de composto orgânico para aveia preta (Avena
}

\author{
strigosa) \\ Maximum technical efficiency dose of organic compost for black oat (Avena strigosa) \\ Dosis de máxima eficiencia técnica de compost orgánico para avena negra (Avena strigosa)
}

Recebido: 01/02/2022 | Revisado: 09/02/2022 | Aceito: 17/02/2022 | Publicado: 25/02/2022

Maiara Figueiredo Ramires ORCID: https://orcid.org/0000-0002-8634-6613 Universidade Estadual do Rio Grande do Sul, Brasil E-mail: maiara.solos@gmail.com

Eduardo Lorensi de Souza

ORCID: https://orcid.org/0000-0003-4834-0066 Universidade Estadual do Rio Grande do Sul, Brasil E-mail: eduardo-souza@uergs.edu.br

Mastrângello Enivar Lanzanova

ORCID: https://orcid.org/0000-0003-2285-1052

Universidade Estadual do Rio Grande do Sul, Brasil

E-mail: mastrangello-lanzanova @uergs.edu.br

Danni Maísa da Silva

ORCID: https://orcid.org/0000-0002-3600-0462

Universidade Estadual do Rio Grande do Sul, Brasil

E-mail: danni-silva@uergs.edu.br

Gustavo Kruger Gonçalves

ORCID: https://orcid.org/0000-0003-4703-3726

Universidade Estadual do Rio Grande do Sul, Brasil

E-mail: gustavo-goncalves@uergs.edu.br

Robson Evaldo Gehlen Bohrer

ORCID: https://orcid.org/0000-0002-2001-8983 Universidade Estadual do Rio Grande do Sul, Brasil E-mail: robson-bohrer@uergs.edu.br

Matheus Rocha

ORCID: https://orcid.org/0000-0002-0878-0924 Universidade Estadual do Rio Grande do Sul, Brasil

E-mail: matheus-rocha@uergs.edu.br

João Eugenio Dias Larssen

ORCID: https://orcid.org/0000-0002-1603-1368

Universidade Estadual do Rio Grande do Sul, Brasil

E-mail: joao-larssen@uergs.edu.br

Edson André Gulart

ORCID: https://orcid.org/0000-0001-5330-5359 Universidade Estadual do Rio Grande do Sul, Brasil

E-mail: edson-gulart@uergs.edu.br

Leonardo de Melo Menezes

ORCID: https://orcid.org/0000-0001-8536-0803 Universidade Estadual do Rio Grande do Sul, Brasil E-mail: leonardo-menezes@uergs.edu.br

\begin{abstract}
Resumo
A suinocultura e a avicultura se destacam dentro do agronegócio, porém, acabam colaborando para a geração de resíduos. Esse trabalho teve por objetivo determinar a dose de máxima eficiência técnica do composto produzido a partir da mistura de diferentes resíduos orgânicos em pastagem de aveia preta com diferentes parcelamentos das aplicações. Os tratamentos foram: adubação mineral; sem adubação; adubação orgânica nas doses (5, 10, 15, 20, 25 e $30 \mathrm{Mg} \mathrm{ha}^{-1}$ ). As doses foram parceladas em uma e duas vezes. Avaliou-se a matéria verde (MV) e seca (MS) aos 45 e 75 dias após emergência, no qual foi obtido a dose de máxima eficiência técnica (DMET), para cada período de corte. $\mathrm{O}$ composto orgânico nas doses de 10 a $30 \mathrm{Mg} \mathrm{ha}^{-1}$ para MV e 15 e $20 \mathrm{Mg} \mathrm{ha}^{-1}$ para MS foi superior a adubação mineral, independente do parcelamento ou não. Já a dose $25 \mathrm{Mg} \mathrm{ha}^{-1}$ para MS, foi superior em aplicação única. A DMET foi encontrada com as doses de 19,1 e 18,7 $\mathrm{Mg} \mathrm{ha}^{-1}$, em aplicação única do composto orgânico, para obtenção do rendimento de 23,9 e 3,0 $\mathrm{Mg} \mathrm{ha}^{-1}$ de MV e MS acumulada, respectivamente. Quando parcelando em duas vezes, a produção máxima de MV acumulada (25,9 $\mathrm{Mg} \mathrm{ha}^{-1}$ ) foi obtida na DMET de 22,9 $\mathrm{Mg} \mathrm{ha}^{-1}$. Já para a MS, a produção máxima acumulada (3,0 $\left.\mathrm{Mg} \mathrm{ha}^{-1}\right)$, foi a partir da DMET de 22,7 $\mathrm{Mg} \mathrm{ha}^{-1}$, respectivamente.
\end{abstract}

Palavras-chave: Resíduos orgânicos; Nitrogênio; Pastagem. 


\begin{abstract}
Pig farming and poultry farming stand out within agribusiness, however, they end up collaborating for the generation of waste. The objective of this work was to determine the maximum technical efficiency dose of the compost produced from the mixture of different organic residues in black oat pasture with different splitting of applications. The treatments were: mineral fertilization; without fertilization; organic fertilization at doses $(5,10,15,20,25$ and 30 $\mathrm{Mg} \mathrm{ha}^{-1}$ ). The doses were divided into once and twice. Green matter (GM) and dry matter (DM) were evaluated at 45 and 75 days after emergence, in which the maximum technical efficiency dose (DMET) was obtained for each cutting period. Organic compost at doses of 10 to $30 \mathrm{Mg} \mathrm{ha}^{-1}$ for GM and 15 and $20 \mathrm{Mg} \mathrm{ha}^{-1}$ for DM was superior to mineral fertilization, regardless of splitting or not. The dose of $25 \mathrm{Mg} \mathrm{ha}^{-1}$ for DM was superior in a single application. DMET was found at doses of 19.1 and $18.7 \mathrm{Mg} \mathrm{ha}^{-1}$, in a single application of the organic compound, to obtain a yield of 23.9 and $3.0 \mathrm{Mg} \mathrm{ha}^{-1}$ of GM and DM accumulated, respectively. When splitting in two installments, the maximum production of accumulated GM (25.9 $\left.\mathrm{Mg} \mathrm{ha}^{-1}\right)$ was obtained at the DMET of $22.9 \mathrm{Mg} \mathrm{ha}^{-1}$. As for DM, the maximum accumulated production (3.0 $\mathrm{Mg} \mathrm{ha}^{-1}$ ) was from the DMET of $22.7 \mathrm{Mg} \mathrm{ha}^{-1}$, respectively.
\end{abstract}

Keywords: Organic waste; Fertilizer; Nitrogen; Grassland.

\title{
Resumen
}

Dentro de la agroindustria se destacan la porcicultura y la avicultura, sin embargo, terminan colaborando para la generación de residuos. El objetivo de este trabajo fue determinar la dosis de máxima eficiencia técnica del compost producido a partir de la mezcla de diferentes residuos orgánicos en pastos de avena negra con diferentes fraccionamientos de aplicaciones. Los tratamientos fueron: fertilización mineral; sin fertilización; fertilización orgánica en dosis $\left(5,10,15,20,25\right.$ y $\left.30 \mathrm{Mg} \mathrm{ha}^{-1}\right)$. Las dosis se dividieron en una y dos veces. La materia verde (MV) y la materia seca (MS) se evaluaron a los 45 y 75 días después de la emergencia, en los cuales se obtuvo la dosis de máxima eficiencia técnica (DMET) para cada período de corte. El compost orgánico en dosis de 10 a $30 \mathrm{Mg} \mathrm{ha}^{-1} \mathrm{para}$ MV y 15 y $20 \mathrm{Mg} \mathrm{ha}^{-1}$ para MS fue superior a la fertilización mineral, independientemente de que se partiera o no. La dosis de $25 \mathrm{Mg} \mathrm{ha}^{-1}$ para MS fue superior en una sola aplicación. Se encontró DMET a dosis de 19.1 y $18.7 \mathrm{Mg} \mathrm{ha}^{-1}$, en una sola aplicación del compuesto orgánico, para obtener un rendimiento de 23.9 y $3.0 \mathrm{Mg} \mathrm{ha}^{-1}$ de MV y MS acumulada, respectivamente. Al fraccionar en dos cuotas, la máxima producción de MV acumulada $\left(25,9 \mathrm{Mg} \mathrm{ha}^{-1}\right) \mathrm{se}$ obtuvo en el DMET de $22,9 \mathrm{Mg} \mathrm{ha}^{-1}$. En cuanto a MS, la máxima producción acumulada $\left(3,0 \mathrm{Mg} \mathrm{ha}^{-1}\right)$ fue de la DMET de 22,7 $\mathrm{Mg} \mathrm{ha}^{-1}$, respectivamente.

Palabras clave: Residuo orgánico; Nitrógeno; Pastar.

\section{Introdução}

No Brasil, a suinocultura e a avicultura são atividades econômicas que se destacam dentro do agronegócio, principalmente nos estados da Região Sul, onde se encontram no cenário nacional como os maiores produtores de suínos e frangos de corte do país (Ramires, et al., 2021; IBGE, 2021). Segundo os dados do IBGE (2021), o Brasil abateu 13,04 milhões de cabeças de suínos no $2^{\circ}$ trimestre de 2021, número que registra um novo recorde para o setor desde 1997 . Desse novo recorde, a Região Sul respondeu por 66,5\% do abate nacional de suínos, seguida pela Sudeste (18,2\%), Centro-Oeste (14,1\%), Nordeste $(1,0 \%)$ e Norte $(0,1 \%)$. Já em relação ao abate de frangos, no $2^{\circ}$ trimestre de 2021 foram abatidas 1,52 bilhão de cabeças. Esse resultado significou aumento de 7,8\% em relação ao mesmo período de 2020, onde a Região Sul respondeu por 60,1\% da participação nacional, no qual o Paraná lidera, com 33,7\%, seguido por Rio Grande Sul (13,2\%) e Santa Catarina $(13,2 \%)$.

Baseado no exposto acima, tanto o setor suinícola, quanto o avícola, há muito tempo tem colaborado para o crescimento econômico no país. Entretanto, concomitantemente acabam colaborando para a geração de um grande acúmulo de resíduos, tais como a cama de aviário, os dejetos, refugos de abate, entre outros. Estima-se que são produzidos em média 2,0 toneladas de cama de aviário para cada 1000 aves com tempo de alojamento de 42 a 49 dias (Mitchell Jr., et al., 1991). Já um suíno pode gerar um volume médio diário de 8,6 litros de dejetos líquido, dependendo da fase que se encontra (Oliveira, 1993). Muitas vezes, esses resíduos acabam sendo dispostos irregularmente em áreas agrícolas sobre a superfície do solo, sem tratamento prévio, o que pode conduzir a contaminação do mesmo por metais e apresentar organismos patogênicos, como bactérias do grupo coliformes (totais e termotolerantes) e por parasitas intestinais, como ovos e larvas de helmintos, o que também inviabiliza o seu uso direto no solo em áreas para produção de alimentos (Pedrosa, et al., 2013; Ramires, et al., 2021). 
De acordo com Rosa (2009), esses tipos de resíduos requerem atenção especial na sua gestão, devido à alta geração, elevada umidade do material e principalmente por dificuldades quanto ao seu destino. Dessa forma, existe a necessidade de desenvolver alternativas que possam reciclar esses materiais e permitir que os mesmos possam ser utilizados em outros setores, como por exemplo, produção de pastagem animal, através da adubação orgânica.

Cada vez mais tem se buscado por alternativas que aumentem os sistemas de produção animal, e a utilização de resíduos orgânicos como fonte de nutrientes para as pastagens pode ser uma delas. Segundo Patzlaff, et al. (2020), animais criados onde o sistema de produção é prioritariamente em pastagens, podem evitar que as propriedades fiquem suscetíveis aos riscos econômicos, quando comparados à sistemas de produção cuja dieta é baseada em milho e soja, pois o preço das commodities sofrem forte influência do mercado.

Durante o inverno, com as baixas temperaturas e as geadas, verifica-se redução na disponibilidade e qualidade das pastagens nativas no Sul do Brasil. Para suprir essa deficiência alimentar são largamente utilizadas pastagens temperadas, como por exemplo, a aveia preta (Avena strigosa) e o azevém (Lollium multiflorum) (Coradini, et al., 2020). Neste sentido, considera-se a importância da adubação dessas pastagens, sendo essa uma prática essencial quando se pretende elevar os níveis produtivos das espécies forrageiras e sua capacidade de suporte animal. Os fertilizantes minerais possuem grande eficiência na disponibilidade de nutrientes para as plantas, entretanto, devido ao seu elevado valor comercial, o produtor pecuarista nem sempre possui condições financeiras suficientes para adquirir em quantidade e qualidade de acordo com a necessidade de correção da fertilidade do solo e de nutrientes exigidos pelas plantas (Rocha Junior, et al., 2016; Macêdo, et al., 2018). Conforme Coradini, et al. (2020), embora o uso de pastagens cultivadas melhore a eficiência produtiva do rebanho, o elevado custo em insumos tem limitado seu uso. Assim sendo, a adubação de pastagens acaba não sendo uma prática rotineira pela maioria dos pecuaristas brasileiros, limitando o potencial das áreas produtivas. Como alternativa de minimizar os custos da adubação, pode-se lançar mão de outras estratégias, como por exemplo o aproveitamento de resíduos orgânicos como fonte total ou parcial de nutrientes (Edvan, et al., 2010; Zanine et al., 2015; Castro, et al., 2016; Sileshi, et al., 2016; Silva, 2017; Gonçalves, et al., 2017; Cardoso, 2019; Schuller, et al., 2020). Entretanto, estudos que utilizem uma mistura de resíduos sólidos que são gerados nos setores suinícola e avícola, como fonte de nutrientes para as plantas, ainda são incipientes.

Por todo exposto, este trabalho teve por objetivo determinar a dose de máxima eficiência técnica do composto produzido a partir da mistura de diferentes resíduos orgânicos em pastagem de aveia preta com diferentes parcelamentos das aplicações.

\section{Metodologia}

O presente estudo foi realizado no ano de 2021, nos meses de maio a outubro, na estação experimental da Cooperativa Tritícola Mista Campo Novo Ltda., Campo Novo - RS, conforme as coordenadas: latitude 27.4049, longitude 53.44958 e altitude média de 468 metros (Figura 1). 
Figura 1 - Vista aérea da área do experimento.

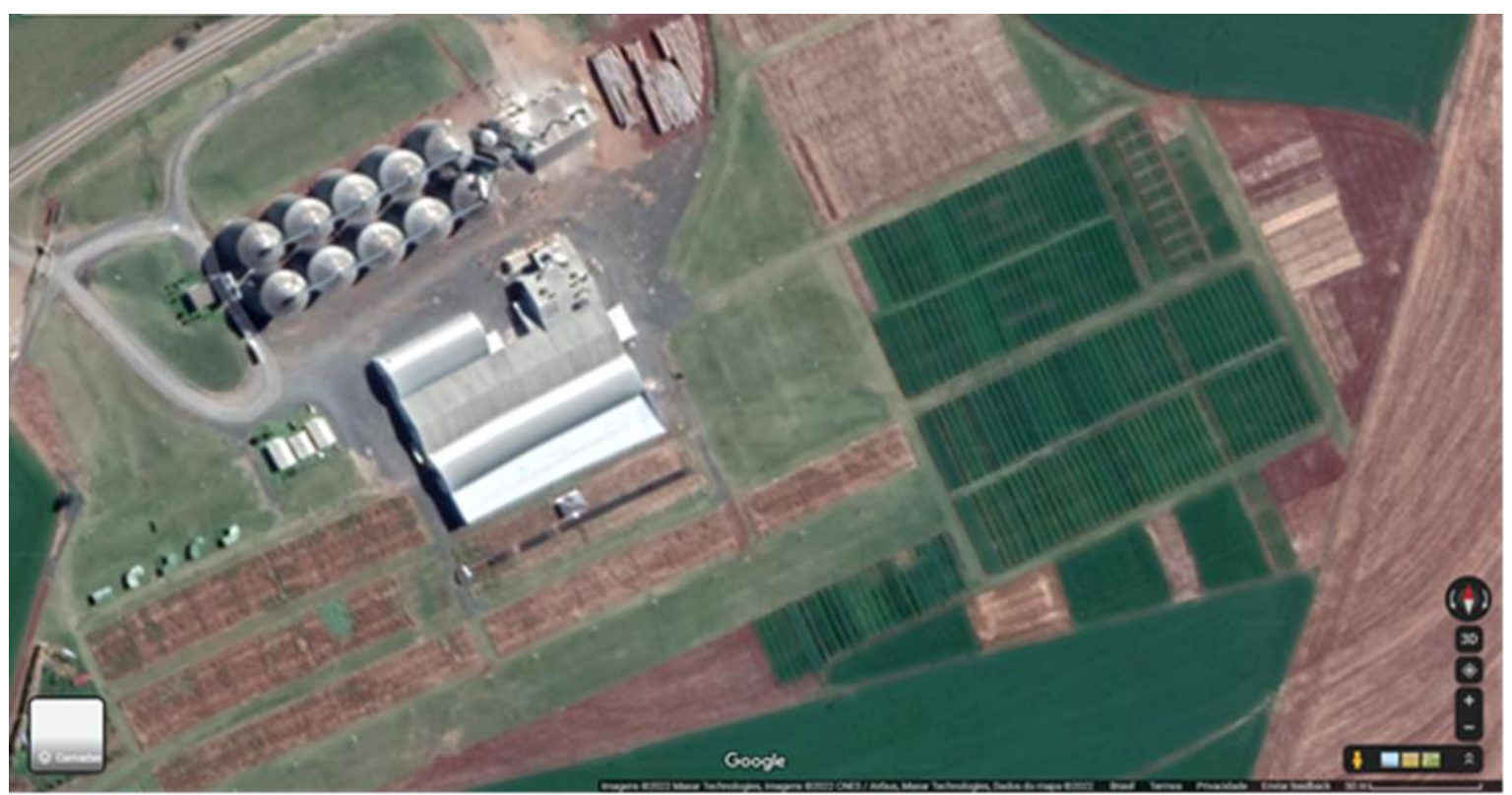

Fonte: Google maps (2022).

O clima do local é tipo Cfa, subtropical úmido, (Köppen, 1931). Os dados de precipitação e temperatura média durante o período do experimento estão apresentados na Figura 2, os quais foram obtidos da estação meteorológica do município de Santo Augusto - RS.

Figura 2 - Precipitação e temperatura média diária durante o período de condução do experimento.

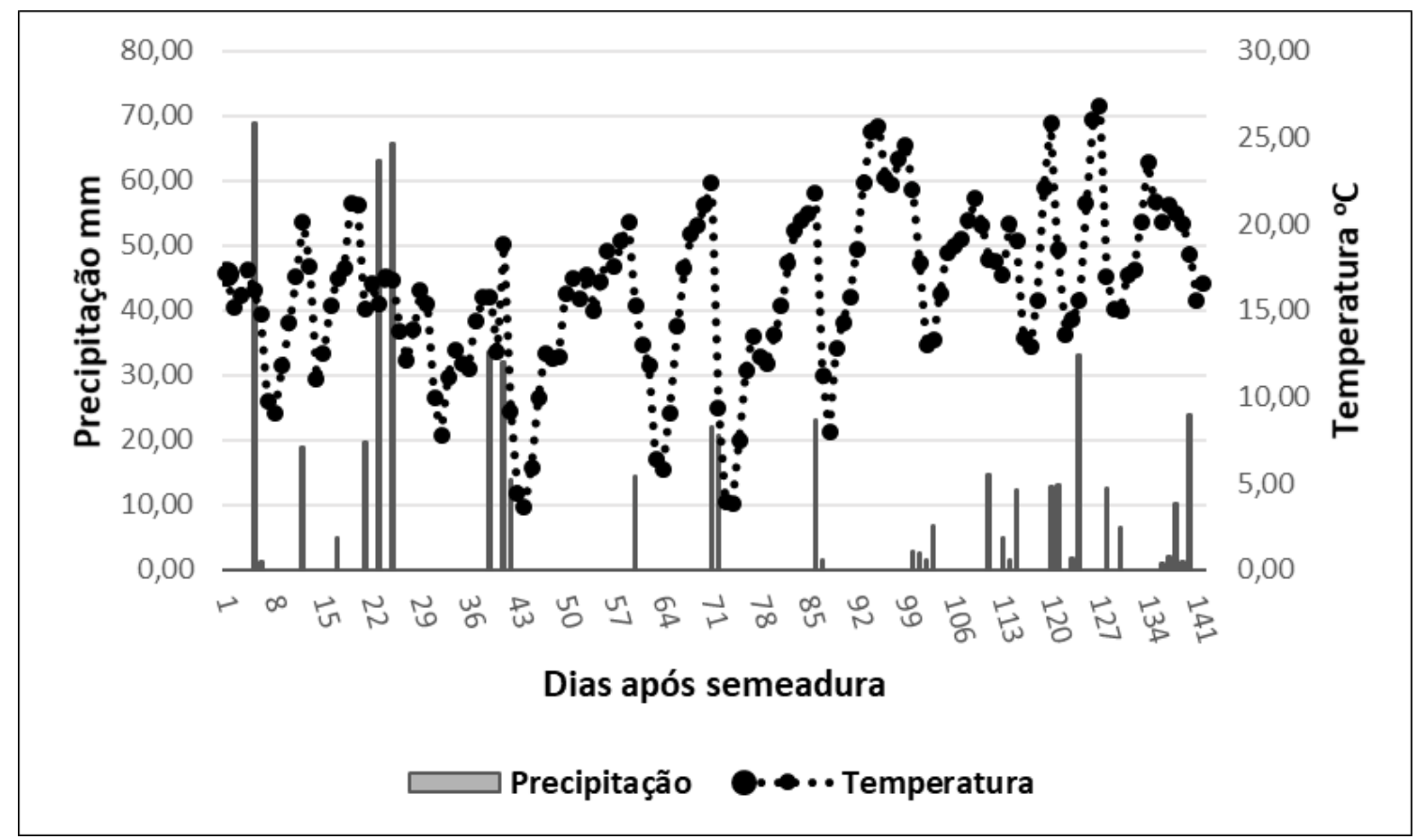

Fonte: Autores.

O solo da área experimental é classificado como Latossolo Vermelho (Santos, et al., 2018). A área onde foi implantado esse estudo vinha sendo utilizada com a cultura do milho em plantio direto, e antes da instalação do experimento 
foi feito a amostragem de solo para a realização da análise química na camada de 0 a $20 \mathrm{~cm}$. Dessa forma, as doses foram definidas a partir da caracterização química do solo (Tabela 1) e do composto orgânico (Tabela 2), baseado na recomendação para nitrogênio (N), conforme o Manual de Calagem e Adubação para os Estados do RS e de SC (CQFS, 2016).

Tabela 1 - Caracterização do solo da área experimental.

\begin{tabular}{cccccccc}
\hline $\begin{array}{c}\text { M.O. } \\
\%\end{array}$ & $\begin{array}{c}\text { Argila } \\
\%\end{array}$ & $\mathrm{pH} \mathrm{em} \mathrm{água}$ & $\begin{array}{c}\mathrm{P} \\
\mathrm{mg} \mathrm{dm}\end{array}$ & $\begin{array}{c}\mathrm{K} \\
\mathrm{mg} \mathrm{dm}\end{array}$ & $\begin{array}{c}\mathrm{Ca} \\
\mathrm{cmol} \mathrm{dm}^{-3}\end{array}$ & $\begin{array}{c}\mathrm{Mg} \\
\mathrm{cmolc} \mathrm{dm}^{-3}\end{array}$ & $\begin{array}{c}\mathrm{CTC} \mathrm{pH}_{7} \\
\mathrm{cmolc} \mathrm{dm}^{-3}\end{array}$ \\
\hline 3,6 & 60,0 & 5,3 & 22,5 & 332,0 & 5,3 & 1,8 & 14,8 \\
\hline
\end{tabular}

*A caracterização do solo foi realizada pelo Laboratório de Análises de Solos e Tecidos Vegetais da Universidade Regional Integrada - URI, conforme Tedesco, et al. (2005). Fonte: Autores.

Tabela 2 - Caracterização do composto.

\begin{tabular}{ccccccccc}
\hline $\mathrm{pH}^{*}$ & Mat. Seca & $\mathrm{C} / \mathrm{N}$ & $\mathrm{C}$ & $\mathrm{N}$ & $\mathrm{P}$ & $\mathrm{K}$ & $\mathrm{Ca}$ & $\mathrm{Mg}$ \\
$\%$ & $\%$ & $\%$ & $\%$ & $\%$ \\
& $\%$ & & $\%$ & $\%$ & 2,89 & 2,03 & 4,30 & 6,33 \\
\hline 7,90 & 78 & $8: 1$ & 23,16 & 2,36 \\
\hline
\end{tabular}

*A caracterização do composto foi realizada pelo Laboratório de Análises de Solos e Tecidos Vegetais da Universidade Regional Integrada URI, conforme Tedesco, et al. (2005). Fonte: Autores.

O composto orgânico utilizado nesse estudo foi obtido de uma empresa que faz o recolhimento e estabilização (compostagem) dos resíduos frescos obtidos de propriedades e de um abatedouro de suínos, situado na Região Norte do estado do Rio Grande do Sul. Esse composto orgânico é produzido a partir da seguinte proporção: $40 \%$ de cama de frango, $25 \%$ de dejetos suínos (pastoso), 20\% de casca de ovo, 10\% de cinzas e 5\% de resíduo de abate suíno.

O delineamento experimental foi em blocos casualizados (DBC), com 8 tratamentos e 4 repetições, totalizando 32 parcelas de 4,0 x 2,3 m (9,2 m²), conforme a descrição que segue: T1 - Aveia preta com adubação mineral NPK (testemunha); T2 - Aveia preta sem adubação (dose zero); T3 - Aveia preta com adubação orgânica (50\% da dose recomendada para N, equivalente a $5 \mathrm{Mg} \mathrm{ha}^{-1}$ ); T4 - Aveia preta com adubação orgânica (100\% da dose recomendada para $\mathrm{N}$, equivalente a $10 \mathrm{Mg}$ ha $\left.^{-1}\right)$; T5 - Aveia preta com adubação orgânica (150\% da dose recomendada para N, equivalente a $\left.15 \mathrm{Mg} \mathrm{ha}^{-1}\right)$; T6 - Aveia preta com adubação orgânica (200\% da dose recomendada para $\mathrm{N}$, equivalente a $20 \mathrm{Mg} \mathrm{ha}^{-1}$ ); T7 - Aveia preta com adubação orgânica (250\% da dose recomendada para N, equivalente a $25 \mathrm{Mg} \mathrm{ha}^{-1}$ ); T8 - Aveia preta com adubação orgânica (300\% da dose recomendada para $\mathrm{N}$, equivalente a $30 \mathrm{Mg} \mathrm{ha}^{-1}$ ).

Para cada tratamento, (exceto os tratamentos testemunha e dose zero) as parcelas de $9,2 \mathrm{~m}^{2}$ foram subdivididas em duas parcelas de $4,6 \mathrm{~m}^{2}$, para também avaliar diferentes formas de parcelamentos da aplicação das doses estudadas. Na primeira forma de parcelamento, as doses foram aplicadas em duas vezes, com uma aplicação, na semeadura, de $60 \mathrm{~kg}^{-1} \mathrm{de}$ N (baseado na dose $100 \%$ e equivalente as demais doses) e o restante da dose em cobertura após o $1^{\circ}$ corte (45 DAE). Já a segunda forma, foi realizada apenas uma vez, com todas as doses de N aplicadas em cobertura aos 25 DAE. Para o tratamento testemunha que recebeu a adubação mineral N-P-K (100-60-0), o nitrogênio foi parcelado em três vezes, sendo a primeira dose $\left(30 \mathrm{~kg} \mathrm{ha}^{-1}\right)$, na semeadura, a segunda dose $\left(30 \mathrm{~kg} \mathrm{ha}^{-1}\right)$ aplicada 25 DAE e o restante após o $1^{\circ}$ corte realizado (45 DAE).

A instalação da pastagem foi realizada por semeadura direta, com espaçamento de $0,17 \mathrm{~m}$ entrelinhas, no dia 17 maio de 2021 sobre a resteva do milho, utilizando-se uma densidade de semeadura de $80 \mathrm{~kg} \mathrm{ha}^{-1}$ de sementes de aveia preta (Avena strigosa), cultivar comum.

Os parâmetros avaliados no presente estudo foram a produção de matéria verde (MV) e seca (MS) da parte aérea da aveia preta aos 45 e 75 DAE. As coletas das amostras para essas avaliações foram realizadas por meio do corte de 3 linhas de 
0,7 metro linear cada, dentro de cada parcela, rebaixando até $10 \mathrm{~cm}$ de altura, para simular um pastejo rotativo. Após o corte, as amostras foram pesadas e acondicionadas em embalagens de papel devidamente identificadas para realização da secagem a $65^{\circ} \mathrm{C}$ até peso constante para determinação da matéria seca.

A dose de máxima eficiência técnica (DMET) foi calculada a partir da equação $y=a x^{2}+b x+c$ referente a matéria verde e seca em cada período de corte (45 e 75 DAE), para ambas as formas de aplicação do composto orgânico, pelo modelo matemático $\mathrm{x}=-\mathrm{b} / 2 \mathrm{a}$ (Tiesdale, et al., 1993).

Os dados obtidos foram submetidos à análise estatística utilizando os procedimentos disponíveis no pacote estatístico Sisvar (Ferreira, 2019), através da análise de regressão linear, e posteriormente foram submetidos à ANOVA, seguida do teste de Dunnett para comparar cada dose contra a testemunha. Posteriormente, pelo teste t LSD (Least Significant Difference), avaliou-se a diferença dos cortes entre os parcelamentos.

\section{Resultados e Discussão}

Os resultados da produção de matéria verde e seca dos dois cortes referentes ao parcelamento das doses em duas aplicações do composto orgânico podem ser observados nas Figuras 3 e 4.

Figura 3 - Matéria verde dos dois cortes referentes ao parcelamento em duas aplicações do composto orgânico.

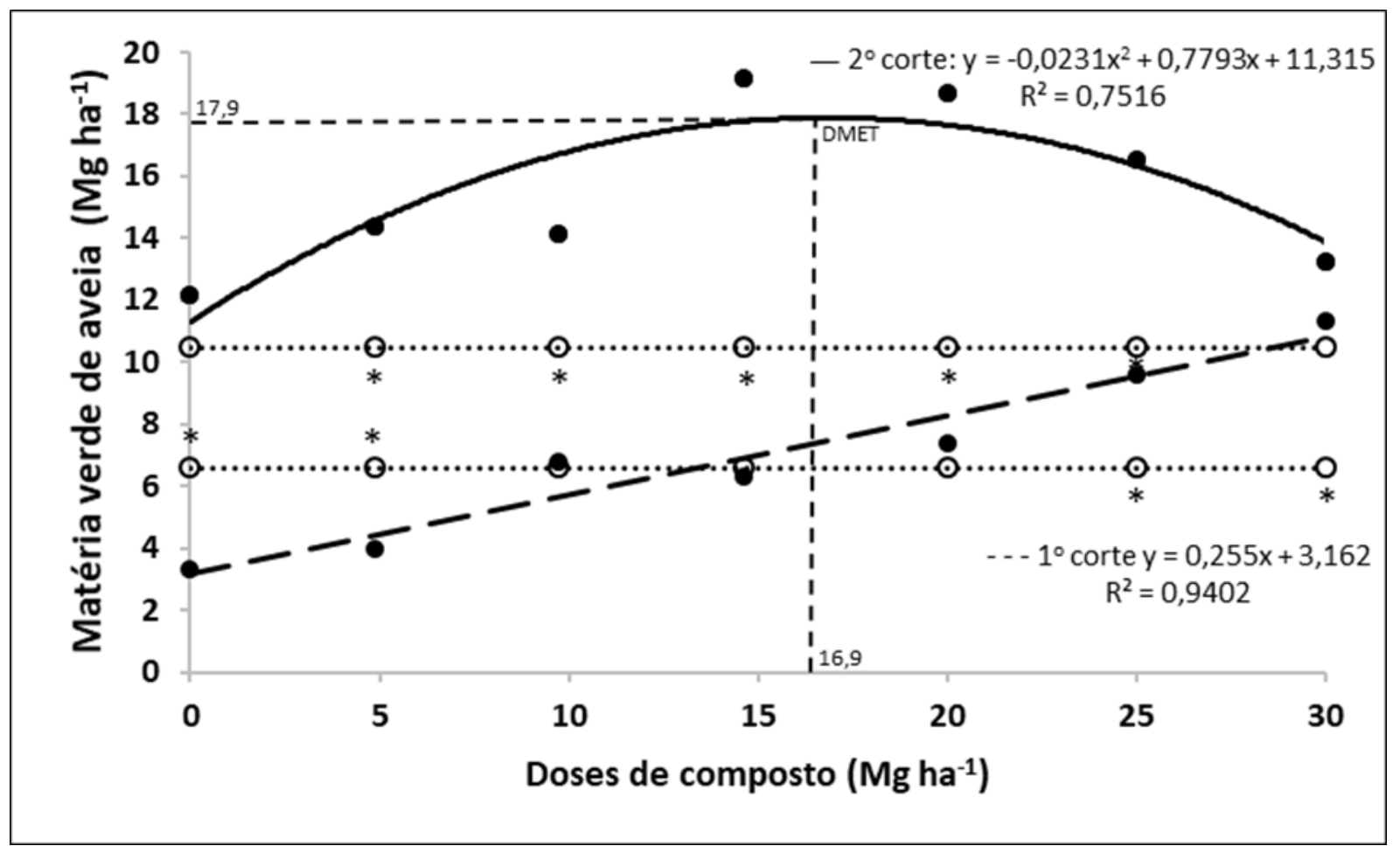

As linhas retas pontilhadas representam os valores da testemunha do $1^{\circ}$ e $2^{\circ}$ corte, respectivamente. $*^{*}=$ indica a diferença significativa de cada dose em relação à testemunha pelo teste Dunnett $(\mathrm{P} \leq 0,05)$. Fonte: Autores. 
Figura 4 - Matéria seca dos dois cortes referentes ao parcelamento em duas aplicações do composto orgânico.

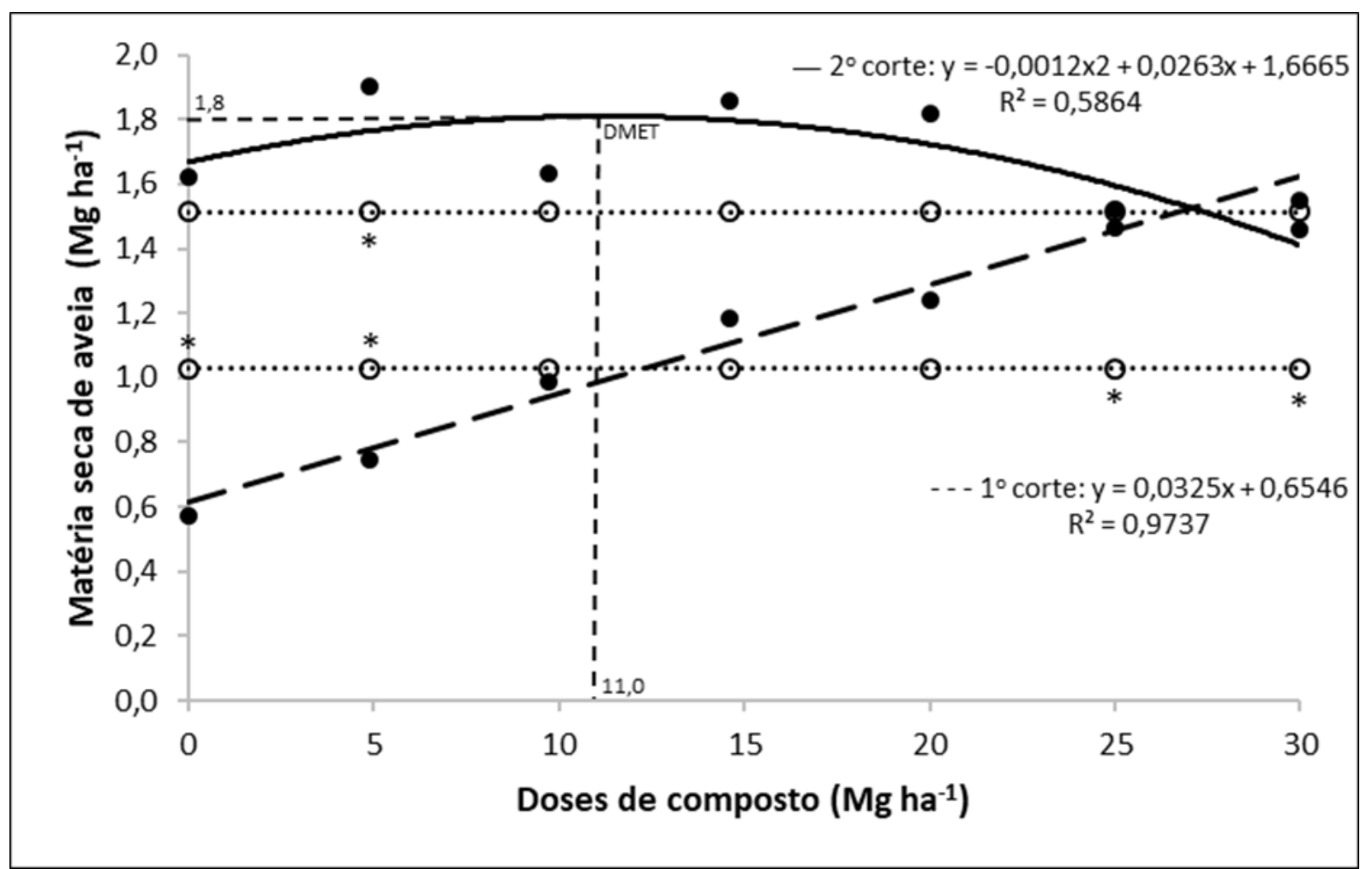

As linhas retas pontilhadas representam os valores da testemunha do $1^{\circ}$ e $2^{\circ}$ corte, respectivamente. * indica a diferença significativa de cada dose em relação à testemunha pelo teste Dunnett $(\mathrm{P} \leq 0,05)$. Fonte: Autores.

Conforme demonstram as figuras acima, analisando a resposta da aveia preta à adubação orgânica, pode-se verificar que à medida que aumentaram as doses, houve um incremento linear, tanto em relação à produção de matéria verde, quanto em produção de matéria seca para o $1^{\circ}$ corte. Isso pode ser explicado em razão do $1^{\circ}$ corte não ter recebido toda a carga de $\mathrm{N}$ necessária a cultura, uma vez que até esse momento, somente os $60 \mathrm{~kg} \mathrm{ha}^{-1}$ tinham sido aplicados na adubação de base. Já para o $2^{\circ}$ corte, houve um ajuste quadrático, no qual a derivada da equação de regressão indicou que a DMET foi de $16,9 \mathrm{Mg}^{-1}$ para obtenção do rendimento de $17,9 \mathrm{Mg} \mathrm{ha}^{-1}$ de MV e DMET de 11,0 $\mathrm{Mg} \mathrm{ha}^{-1}$ com um rendimento de $1,8 \mathrm{Mg}^{-1}$ de $\mathrm{MS}$. Castro, et al. (2016), avaliando o efeito de doses de esterco bovino, no desenvolvimento de duas forrageiras tropicais, verificaram no $1^{\circ}$ corte por meio da equação de regressão, aumento linear na produtividade de massa seca da Brachiaria brizantha (Syn. Uroclhoa brizantha) cv. Marandu em função das doses de esterco. Por outro lado, no $2^{\circ}$ corte a produção de massa seca em função das doses de esterco se ajustaram a uma regressão quadrática, com o ponto de máxima estimado em 25,5 $\mathrm{Mg} \mathrm{ha}^{-1}$ de esterco. O mesmo ocorreu para o $3^{\circ}$ corte, porém, o ponto de máxima foi obtido com a dose de $20,5 \mathrm{Mg}^{-1}$. Já o Panicun maximum cv. Mombaça respondeu com um aumento linear até a dose máxima aplicada $\left(36,0 \mathrm{Mg} \mathrm{ha}^{-1}\right)$.

Também, observando os valores absolutos, se verificou que a intensidade de resposta à adubação orgânica variou em função da época de corte, sendo observado um acúmulo superior de matéria verde e seca no $2^{\circ}$ corte. Isso provavelmente ocorreu devido ao estímulo que a planta sofreu após o $1^{\circ}$ corte, pois o mesmo acabou proporcionando respostas morfofisiológicas na planta. Segundo Ferraro \& Oesterheld (2002), essa é uma resposta comum da planta ao pastejo, sendo este influenciado por diversos mecanismos. Dentre esses, está a maior alocação de carboidratos, que estavam armazenados no colmo e raízes, para as folhas. Além disso, ocorre também a mobilização de reservas de nitrogênio, das raízes e caules para as folhas em desenvolvimento (Liu et al., 2010). Ainda, após a desfolha, ocorre maior penetração da luz solar no dossel da planta, havendo maior atividade fotossintética, remoção de folhas velhas e ativação de meristemas dormentes (Costa, et al., 2004). 
Em relação a comparação de cada dose contra a testemunha, foi possível observar que no $1^{\circ}$ corte, para a produção de matéria verde, a testemunha mostrou-se significativamente superior $\left(6,60 \mathrm{Mg} \mathrm{ha}^{-1}\right)$ comparada as doses 0 e $5 \mathrm{Mg}^{-1}$, que produziram 3,31 e 4,01 $\mathrm{Mg} \mathrm{ha}^{-1}$, respectivamente. Já para as demais doses, não houve diferença significativa, exceto para as doses 25 e $30 \mathrm{Mg} \mathrm{ha}^{-1}$ que foram significativamente superiores a testemunha, com uma produção de 9,59 e 11,34 $\mathrm{Mg}^{-1}$ de MV, respectivamente. Para a matéria seca do $1^{\circ}$ corte, o comportamento foi semelhante a matéria verde, no qual a testemunha também se mostrou significativamente superior $\left(1,03 \mathrm{Mg} \mathrm{ha}^{-1}\right)$ em comparação as doses 0 e $5 \mathrm{Mg} \mathrm{ha}^{-1}\left(0,57\right.$ e $0,75 \mathrm{Mg}^{-1}$, respectivamente), e significativamente inferior em relação as doses 25 e $30 \mathrm{Mg} \mathrm{ha}^{-1}$ (1,52 e 1,55 Mg ha-1, respectivamente), não diferindo estatisticamente das demais doses.

Para a matéria verde do $2^{\circ}$ corte, a testemunha $\left(10,49 \mathrm{Mg} \mathrm{ha}^{-1}\right)$, foi significativamente inferior em comparação a todas as doses estudadas do composto orgânico, exceto na dose 0 e $30 \mathrm{Mg} \mathrm{ha}^{-1}$, que não se observou diferença significativa em relação a mesma. Já para a matéria seca do $2^{\circ}$ corte, apesar de em valores absolutos a testemunha $\left(1,51 \mathrm{Mg}^{-1}\right)$ ter sido inferior em relação as doses $0,5,10,15$ e $20 \mathrm{Mg} \mathrm{ha}^{-1}$ e próxima as doses 25 e $30 \mathrm{Mg} \mathrm{ha}^{-1}$, apresentou diferença significativa somente em comparação a dose $5 \mathrm{Mg} \mathrm{ha}^{-1}$.

Os resultados obtidos nesse estudo são importantes tanto do ponto de vista técnico quanto econômico, pois além de mostrarem que os resíduos orgânicos podem ser transformados para reduzir aspectos como impactos ambientais, ainda podem ser fonte de nutrientes que tem potencial de incrementar as produtividades com custo reduzido através de um insumo produzido na própria região de produção agrícola, além de resolver um possível problema que pode impactar o solo e os recursos hídricos negativamente. A produção e utilização desse resíduo em forma de composto biofertilizante também impacta de forma a reduzir os valores que os agricultores precisam investir buscando fertilizantes de fora da propriedade, visto que a cada ano este custo e a escassez vem aumentando e trazendo impactos financeiros negativos dentro da cadeia produtiva.

Os resultados da produção de matéria verde e seca dos dois cortes, referentes a aplicação única das doses do composto orgânico podem ser observados nas Figuras 5 e 6.

Figura 5 - Matéria verde dos dois cortes em aplicação única do composto orgânico.

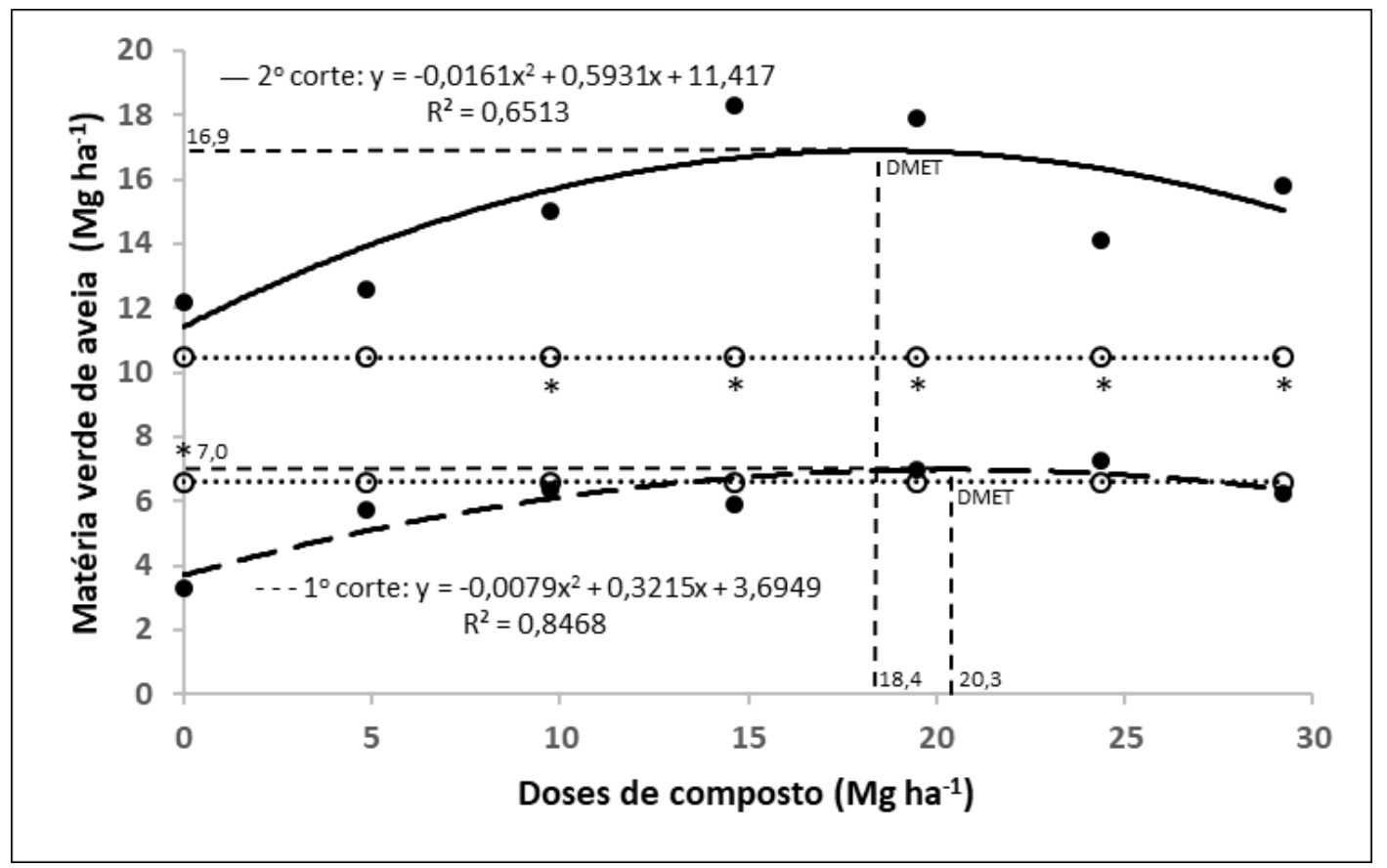

As linhas retas pontilhadas representam os valores da testemunha do $1^{\circ}$ e $2^{\circ}$ corte, respectivamente. $*=$ indica a diferença significativa de cada dose em relação à testemunha pelo teste Dunnett $(\mathrm{P} \leq 0,05)$. Fonte: Autores. 
Figura 6 - Matéria seca dos dois cortes em aplicação única do composto orgânico.

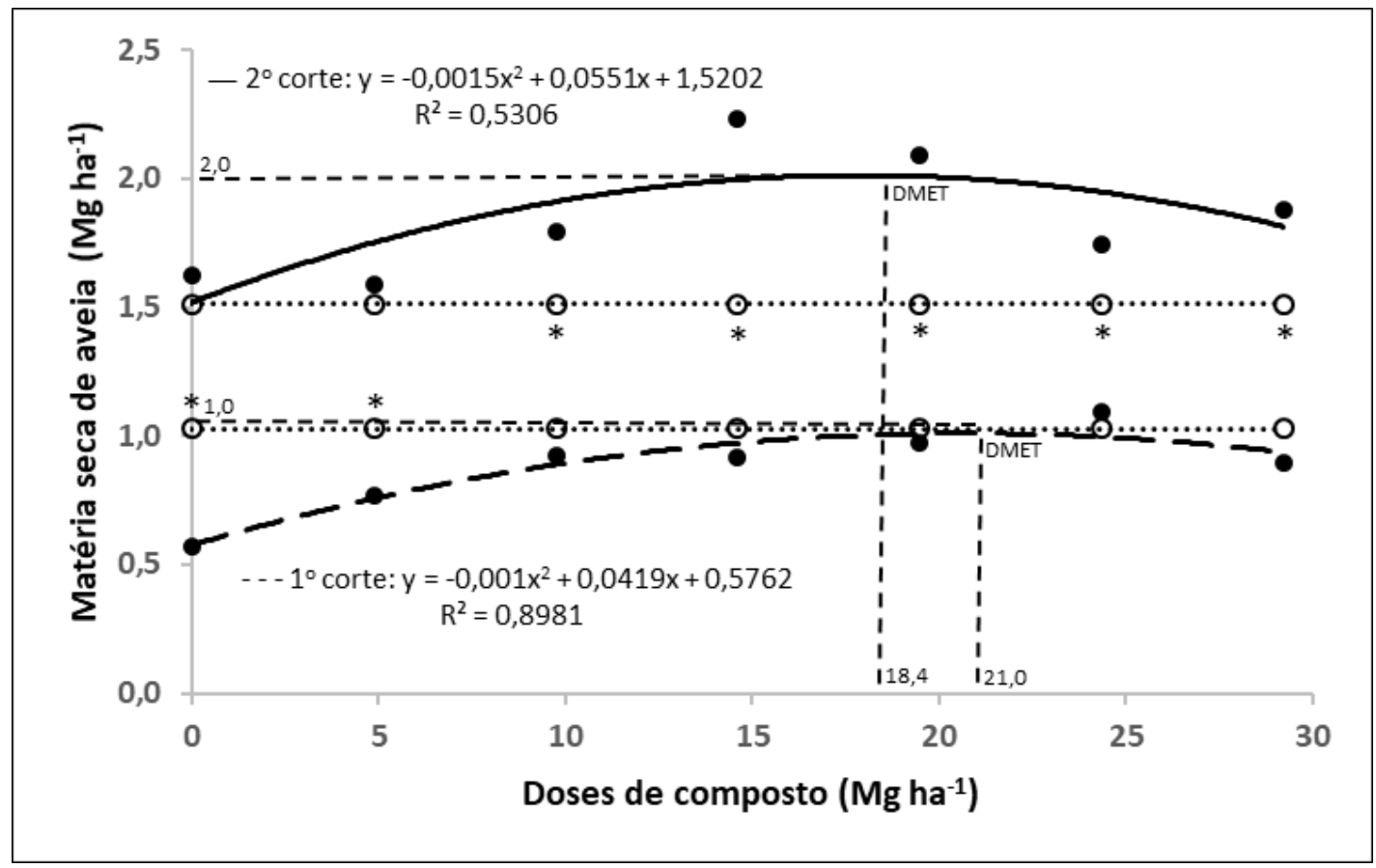

As linhas retas pontilhadas representam os valores da testemunha do $1^{\circ}$ e $2^{\circ}$ corte, respectivamente. $*=$ indica a diferença significativa de cada dose em relação à testemunha pelo teste Dunnett $(\mathrm{P} \leq 0,05)$. Fonte: Autores.

Para o $1^{\circ}$ e $2^{\circ}$ corte houve ajuste quadrático para a produção de matéria verde e seca. De acordo com as equações, a DMET estimadas em 20,3 e 21,0 $\mathrm{Mg} \mathrm{ha}^{-1}$ de composto orgânico proporcionaram a máxima produção (7,0 e 1,0 Mg ha-1 de MV e MS, respectivamente), no $1^{\circ}$ corte. Já para o $2^{\circ}$ corte a produção máxima de matéria verde e seca $\left(16,9\right.$ e $2,0 \mathrm{Mg}$ ha ${ }^{-1}$, respectivamente), foi obtida na DMET de $18,4 \mathrm{Mg}^{-1}$ do composto orgânico. Cabe aqui destacar, que o mesmo comportamento de um acúmulo superior de matéria verde e seca no $2^{\circ}$ corte, também foi observado, como já explicado na discussão anterior. Em estudo realizado por Schüller, et al. (2020), os autores verificaram um incremento linear na produção de matéria verde e seca do Lolium multiflorum L. cv. BRS Ponteio, nos três cortes avaliados com 5 doses (0, 37, 74, 111 e 148 T $h^{-1}$ ) de adubação orgânica à base de esterco bovino incorporadas ao solo anteriormente a semeadura.

Na comparação de cada dose contra a testemunha $\left(6,60 \mathrm{Mg} \mathrm{ha}^{-1}\right)$, foi possível verificar que para a produção de matéria verde do $1^{\mathrm{o}}$ corte, somente a dose $0 \mathrm{Mg} \mathrm{ha}^{-1}\left(3,31 \mathrm{Mg} \mathrm{ha}^{-1}\right)$ mostrou-se significativamente inferior, e as demais doses não apresentaram diferença significativa. Para matéria seca, as doses 0 e $5 \mathrm{Mg} \mathrm{ha}^{-1}\left(0,57\right.$ e $0,77 \mathrm{Mg}^{-1}$, respectivamente), foram significativamente inferiores a testemunha $\left(1,03 \mathrm{Mg} \mathrm{ha}^{-1}\right)$, não havendo diferença significativa para as demais doses. Para o $2^{\circ}$ corte, em números absolutos, todas as doses foram superiores a testemunha $\left(10,49\right.$ e 1,51 $\left.\mathrm{Mg} \mathrm{ha}^{-1}\right)$, para a produção de matéria verde e seca, respectivamente, mas somente a partir da dose $10 \mathrm{Mg} \mathrm{ha}^{-1}$ do composto orgânico é que houve diferença estatística. Bratti (2013), estudando doses e tipos de cama de frango na resposta da Avena strigosa cv. IAPAR 61, verificou um ajuste quadrático de regressão polinomial quando com cama de aviário de corte. Já para cama de aviário de postura, o modelo foi o linear. $\mathrm{O}$ autor também concluiu que a produção de forragem de aveia preta foi maior quando usada cama de aviário de frango de corte se comparado a cama de aviário de postura, superando a produção de forragem obtida com adubação mineral nas doses acima de 6,5 $\mathrm{Mg} \mathrm{ha}^{-1}$ de cama e com máxima produção na dose de $13 \mathrm{Mg} \mathrm{ha}^{-1}$ de cama. Araújo, et al. (2009) estudaram o efeito de duas doses de dois compostos orgânicos semicurados $\left(20\right.$ e $40 \mathrm{Mg} \mathrm{ha}^{-1}$ de composto de esterco bovino, e 10 e $20 \mathrm{Mg} \mathrm{ha}^{-1}$ de composto de esterco de galinha) e de adubação mineral nitrogenada no desenvolvimento de Brachiaria decumbens (Syn. Uroclhoa decumbens), com ambas as fontes de $\mathrm{N}$ em aplicação única. Os autores observaram que a adubação 
mineral proporcionou maior altura de plantas quando comparado aos demais tratamentos e atribuíram este resultado ao fato da maior resposta da forrageira ao N prontamente disponível. Porém, para a produtividade de massa seca da parte aérea os autores não verificaram diferença entre as fontes estudadas. Castro, et al. (2016), observaram que a adubação mineral proporcionou resultados semelhantes às duas maiores doses de esterco bovino aplicadas (18 e $27 \mathrm{Mg} \mathrm{ha}^{-1}$ para a Brachiaria brizantha e 18 e $36 \mathrm{Mg} \mathrm{ha}^{-1}$ para a Panicun maximum.

Os resultados da produção de matéria verde e seca acumulada (soma dos dois cortes), referentes a aplicação única das doses do composto orgânico e em aplicação parcelada em duas vezes, podem ser observados nas Figuras 7 e 8.

Figura 7 - Matéria verde acumulada nos dois cortes com aplicação única ou em duas aplicações do composto orgânico,

respectivamente.

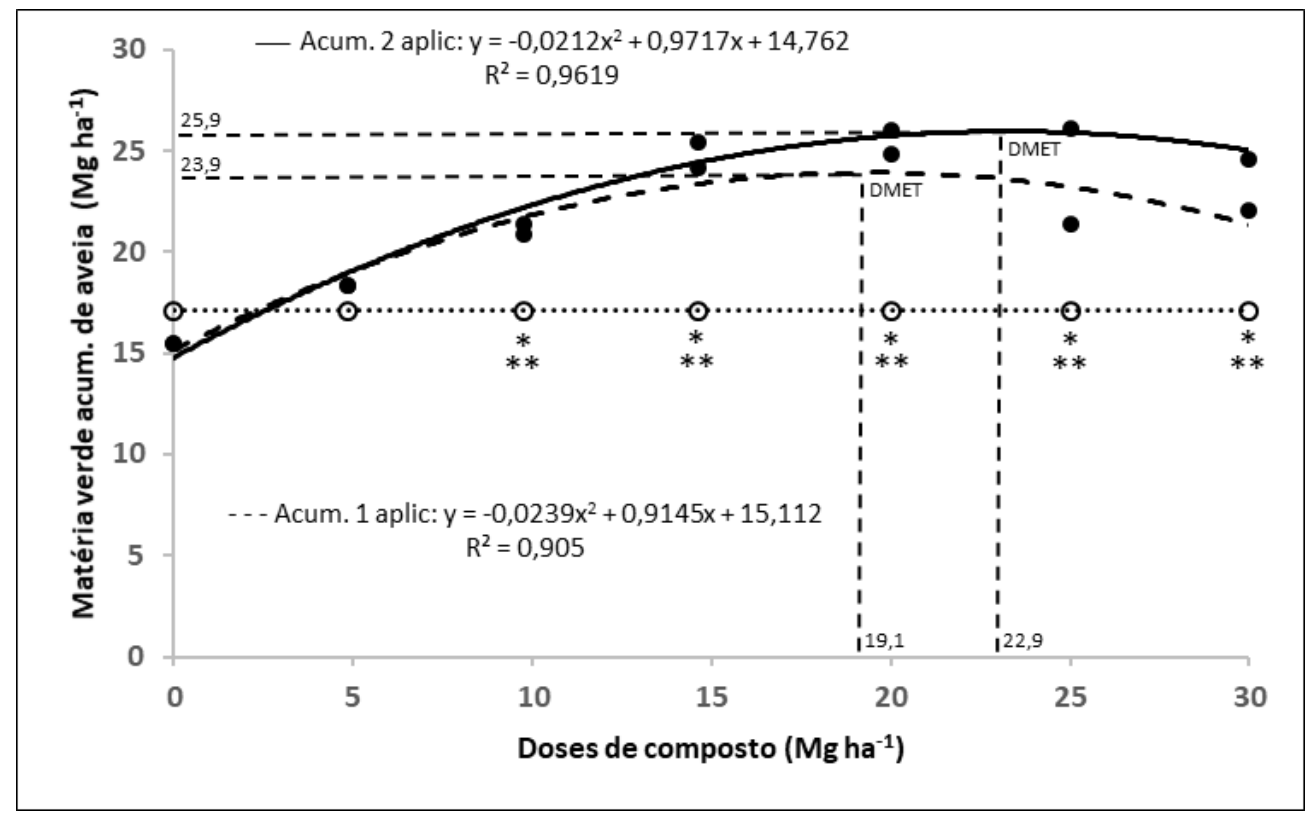

A linha reta pontilhada representa os valores acumulados da testemunha. *= indica a diferença significativa de cada dose em relação a testemunha em aplicação única do composto orgânico pelo teste Dunnett $(\mathrm{P} \leq 0,05)$.**= indica a diferença significativa de cada dose em relação a testemunha referente ao parcelamento do composto orgânico em duas aplicações pelo teste Dunnett $(\mathrm{P} \leq 0,05)$. Fonte: Autores. 
Figura 8 - Matéria seca acumulada nos dois cortes com aplicação única e duas aplicações do composto orgânico, respectivamente.

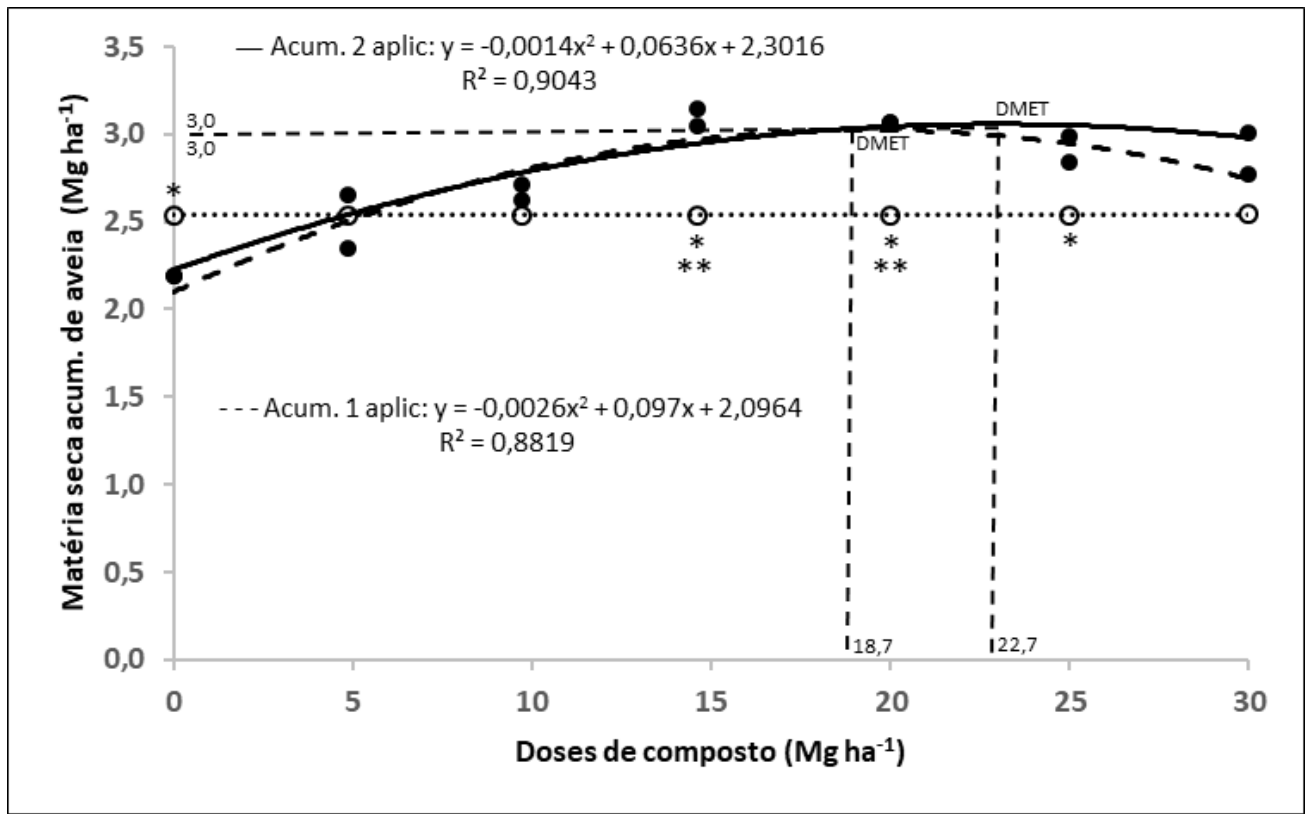

A linha reta pontilhada, representa os valores acumulados da testemunha. $*=$ indica a diferença significativa de cada dose em relação a testemunha em aplicação única do composto orgânico pelo teste Dunnett $(\mathrm{P} \leq 0,05)$. **=indica a diferença significativa de cada dose em relação a testemunha referente ao parcelamento do composto orgânico em duas aplicações pelo teste Dunnett $(\mathrm{P} \leq 0,05)$. Fonte: Autores.

Conforme demonstram as figuras acima, quando analisamos a matéria verde acumulada pode-se verificar que para ambas as formas de aplicação do composto orgânico, houve um ajuste quadrático. Dessa maneira, quando aplicado em uma vez, a derivada da equação de regressão indicou que a DMET foi de 19,1 $\mathrm{Mg} \mathrm{ha}^{-1}$ para obtenção do rendimento de $23,9 \mathrm{Mg}$ ha ${ }^{1}$ de MV e DMET de 18,7 $\mathrm{Mg} \mathrm{ha}^{-1}$ com um rendimento de 3,0 $\mathrm{Mg}^{-1}$ de $\mathrm{MS}$. Esse mesmo comportamento quadrático foi observado em relação a aplicação parcelada em duas vezes do composto orgânico, porém, a produção máxima de matéria verde acumulada $\left(25,9 \mathrm{Mg} \mathrm{ha}^{-1}\right)$ foi obtida na DMET de 22,9 $\mathrm{Mg} \mathrm{ha}^{-1}$. Já para a matéria seca, a produção máxima acumulada (3.0 $\mathrm{Mg} \mathrm{ha}^{-1}$ ), foi a partir da estimativa da DMET de 22,7 $\mathrm{Mg} \mathrm{ha}^{-1}$. Schüller, et al. (2020) verificaram uma produção de matéria seca acumulada do Lolium multiflorum L. cv. BRS Ponteio, inferior aos $3000 \mathrm{~kg} \mathrm{ha}^{-1}$ na dose máxima estudada (148 T ha-1). Os autores atribuíram a baixa produção de massa seca observada no experimento devido às condições climáticas observadas ao longo do mesmo, que foram caracterizadas por apresentar temperaturas frequentes inferiores a temperatura base mínima da cultura $\left(7^{\circ} \mathrm{C}\right)$.

Na comparação da matéria verde acumulada contra a testemunha (17,09 $\left.\mathrm{Mg} \mathrm{ha}^{-1}\right)$, para ambas as formas de aplicação, as doses 10, 15, 20, 25 e $30 \mathrm{Mg} \mathrm{ha}^{-1}$, foram significativamente superiores. Já para a matéria seca acumulada, quando em aplicação única, a dose $0 \mathrm{Mg} \mathrm{ha}^{-1}$ foi significativamente inferior a testemunha $\left(2,54 \mathrm{Mg} \mathrm{ha}^{-1}\right)$. Por outro lado, as doses 15,20 e

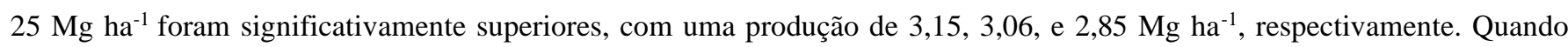
aplicado em duas vezes, somente as doses 15 e $20 \mathrm{Mg} \mathrm{ha}^{-1}$, apresentaram diferença significativa superior em relação a testemunha, com uma produção de 3,04 e 3,06 $\mathrm{Mg} \mathrm{ha}^{-1}$ de MS acumulada, respectivamente. Esses resultados estão de acordo as Indicações Técnicas da Cultura da Aveia (2014), que estima, dependendo da cultivar, um rendimento médio de 2,0 a 4,0 Mg ha $^{-1}$ de matéria seca para a aveia preta, quando a mesma é utilizada para pastejo, ou seja, passando por vários cortes até o florescimento. Ao contrário de quando é utilizada para cobertura de solo, na qual pode produzir de 5,0 a 8,0 $\mathrm{Mg}^{-1}$, sendo essa produção mensurada com um corte único no florescimento. Dessa forma, o uso de fontes orgânicas como fertilizantes pode ser vantajoso economicamente e significa o uso mais racional dos nutrientes desses materiais da atividade agroindustrial. 
Segundo Barbosa, et al. (2009), a aplicação de resíduos orgânicos pode complementar ou até mesmo substituir a adubação mineral em algumas culturas. Além disso, a adubação orgânica proporciona a longo prazo, benefícios na parte química, física e biológica do solo, devido ao acúmulo de matéria orgânica no mesmo (Malavolta, 2006).

$\mathrm{Na}$ Tabela 3 pode-se verificar o efeito das doses do composto orgânico aplicados de forma única ou parcelado em duas vezes, nos resultados de produção de matéria verde e seca de aveia preta.

Tabela 3 - Valores médios de matéria verde e seca dos dois cortes com uma e duas aplicações do composto orgânico.

\begin{tabular}{|c|c|c|c|c|}
\hline \multirow{3}{*}{ Tratamento } & \multicolumn{4}{|c|}{ Matéria verde $\left(\mathrm{Mg} \mathrm{ha}^{-1}\right)$} \\
\hline & \multicolumn{2}{|c|}{$1^{\circ}$ corte $(45 \mathrm{DAE})$} & \multicolumn{2}{|c|}{$2^{\circ}$ corte (75 DAE) } \\
\hline & 1 aplicação & 2 aplicações & 1 aplicação & 2 aplicações \\
\hline 0 & $3,3^{n s}$ & 3,3 & $12,2^{n s}$ & 12,2 \\
\hline 5 & $5,7^{n s}$ & 4,0 & $12,6^{n s}$ & 14,4 \\
\hline 10 & $6,4^{n s}$ & 6,8 & $15,0^{n s}$ & 14,1 \\
\hline 15 & $5,9^{n s}$ & 6,3 & $18,3^{n s}$ & 19,2 \\
\hline 20 & $7,0^{n s}$ & 7,4 & $17,9^{n s}$ & 18,7 \\
\hline 25 & $7,3^{n s}$ & 9,6 & $14,1^{n s}$ & 16,5 \\
\hline 30 & $6,2 b^{*}$ & $11,3 \mathrm{a}$ & $15,8 \mathrm{a}$ & $13,3 \mathrm{~b}$ \\
\hline Testemunha & $6,6^{\mathrm{ns}}$ & 6,6 & $10,5^{n s}$ & 10,5 \\
\hline
\end{tabular}

\begin{tabular}{|c|c|c|c|c|}
\hline \multirow{3}{*}{ Tratamento } & \multicolumn{4}{|c|}{ Matéria seca $\left(\mathrm{Mg} \mathrm{ha}^{-1}\right)$} \\
\hline & \multicolumn{2}{|c|}{$1^{\circ}$ corte (45 DAE) } & \multicolumn{2}{|c|}{$2^{\circ}$ corte $(75 \mathrm{DAE})$} \\
\hline & 1 aplicação & 2 aplicações & 1 aplicação & 2 aplicações \\
\hline 0 & $0,6^{n s}$ & 0,6 & $1,6^{n s}$ & 1,6 \\
\hline 5 & $0,8^{n s}$ & 0,7 & $1,6^{n s}$ & 1,9 \\
\hline 10 & $0,9^{n s}$ & 1,0 & $1,8^{n s}$ & 1,6 \\
\hline 15 & $0,9^{n s}$ & 1,2 & $2,2 \mathrm{a}$ & $1,9 \mathrm{~b}$ \\
\hline 20 & $1,0^{n s}$ & 1,2 & $2,1 \mathrm{a}$ & $1,8 \mathrm{~b}$ \\
\hline 25 & $1,1^{n s}$ & 1,5 & $1,7^{n s}$ & 1,5 \\
\hline 30 & $0,9 \mathrm{~b}$ & $1,5 \mathrm{a}$ & $1,9^{n s}$ & 1,5 \\
\hline \multirow[t]{2}{*}{ Testemunha } & $1,0^{n s}$ & 1,0 & $1,5^{n s}$ & 1,5 \\
\hline & \multicolumn{4}{|c|}{ Matéria acumulada $\left(\mathrm{Mg} \mathrm{ha}^{-1}\right)$} \\
\hline \multirow[t]{2}{*}{ Tratamento } & \multicolumn{2}{|c|}{ MV } & \multicolumn{2}{|c|}{ MS } \\
\hline & 1 aplicação & 2 aplicações & 1 aplicação & 2 aplicações \\
\hline 0 & $15,5^{n s}$ & 15,5 & $2,2^{n s}$ & 2,2 \\
\hline 5 & $18,3^{n s}$ & 18,4 & $2,4^{n s}$ & 2,7 \\
\hline 10 & $21,4^{n s}$ & 20,9 & $2,7^{n s}$ & 2,6 \\
\hline 15 & $24,2^{n s}$ & 25,5 & $3,1^{n s}$ & 3,0 \\
\hline 20 & $24,9 \mathrm{~b}$ & $26,0 \mathrm{a}$ & $3,1^{n s}$ & 3,1 \\
\hline 25 & $21,4^{n s}$ & 26,1 & $2,8^{n s}$ & 3,0 \\
\hline 30 & $22,1 \mathrm{~b}$ & $24,6 \mathrm{a}$ & $2,8^{n s}$ & 3,0 \\
\hline Testemunha & $17,1^{n s}$ & 17,1 & $2,5^{n s}$ & 2,5 \\
\hline
\end{tabular}

*Letras iguais nas linhas, dentro de cada período de corte (45 e 75 DAE), e para a matéria verde e seca acumulada indicam existência de diferença estatística significativa pelo teste $\mathrm{t} \operatorname{LSD}(\mathrm{P} \leq 0,05)$, em relação a uma e duas aplicações. ${ }^{n s}$ não significativo pelo teste $t \mathrm{LSD}(\mathrm{P}$ $\leq 0,05)$. Fonte: Autores. 
Conforme se observa na tabela acima, para a matéria verde somente a dose $30 \mathrm{Mg} \mathrm{ha}^{-1}$ apresentou diferença estatística na comparação entre as formas de aplicações, para os dois cortes realizados nesse estudo. Assim sendo, para o $1^{\text {a }}$ corte, a aplicação em duas vezes se mostrou significativamente superior $\left(11,3 \mathrm{Mg} \mathrm{ha}^{-1}\right)$ em relação a aplicação única $\left(6,2 \mathrm{Mg}^{-1}\right)$. Por outro lado, para o $2^{\circ}$ corte essa diferença ocorreu ao contrário dentro da mesma dose, ou seja, a aplicação única foi significativamente superior (15,8 $\left.\mathrm{Mg} \mathrm{ha}^{-1}\right)$, comparada a aplicação de composto orgânico parcelada em duas vezes (13,3 Mg $\left.\mathrm{ha}^{-1}\right)$.

Para a matéria seca, os resultados mostraram que para o $1^{\circ}$ corte, novamente a dose de $30 \mathrm{Mg}^{-1}$ apresentou diferença significativa na comparação entre as formas de aplicação. A aplicação parcelada em duas vezes se mostrou significativamente superior (1,5 $\left.\mathrm{Mg} \mathrm{ha}^{-1}\right)$, comparada a aplicação única, que produziu 0,9 $\mathrm{Mg} \mathrm{ha}^{-1}$ de MS. Esses resultados do $1^{\mathrm{o}}$ corte sugerem que, em um primeiro momento, o parcelamento de doses mais elevadas pode proporcionar um melhor aproveitamento do $\mathrm{N}$ pela pastagem e evitar perdas relacionadas a lixiviação de nitrato $\left(\mathrm{NO}_{3}^{-}\right)$, a volatilização de amônia $\left(\mathrm{NH}_{3}\right)$ e a emissão de óxido nitroso $\left(\mathrm{N}_{2} \mathrm{O}\right)$ (Aita, et al., 2014; CQFS, 2016). No $2^{\circ}$ corte, as doses 15 e $20 \mathrm{Mg}^{-1}$ apresentaram diferença significativa, nas quais a aplicação única mostrou-se superior com uma produção de 2,2 e $2,1 \mathrm{Mg}^{-1}$ de $\mathrm{MS}$, respectivamente, quando comparada com a aplicação em duas vezes (1,9 e 1,8 $\left.\mathrm{Mg} \mathrm{ha}^{-1}\right)$. Em estudo realizado por Carvalho, et al. (2016), onde avaliaram o efeito de doses e formas de aplicação da adubação com cama de frango na produtividade de Tifton 85 (Cynodon nlemfuensis Vandeyst x Cynodon dactylon (L.) Pers.), os autores verificaram que as formas de aplicação da cama de frango não influenciaram o acúmulo de fitomassa, independente da época de coleta da pastagem.

Para os cortes acumulados, somente a matéria verde apresentou diferença significativa nas doses 20 e $30 \mathrm{Mg}^{-1}$, onde a aplicação parcelada em duas vezes foi significativamente superior (26,0 e 24,6 $\mathrm{Mg} \mathrm{ha}^{-1}$, respectivamente). De forma geral, pode-se verificar que apesar do Manual de Calagem e Adubação para os Estados do RS e de SC (CQFS, 2016), recomendar parcelamento do $\mathrm{N}$, independente da fonte de adubação utilizada, a aplicação em dose única do composto orgânico utilizado nesse estudo pode se tornar uma alternativa viável sem comprometer a produção da pastagem. O parcelamento nem sempre é a maneira mais rentável para o produtor, pois, pode gerar um aumento significativo nos gastos com mão de obra e provocar compactação do solo, devido ao maior tráfego de maquinários na área. Isso é muito importante, especialmente do ponto de vista da redução de custos com operações agrícolas de entradas e reentradas na lavoura para a aplicação e também quanto às doses a serem aplicadas para se obter as melhores produtividades. Estes aspectos quando observados numa visão holística da propriedade, permitem ao produtor definir estratégias que reduzam custos e mão de obra e maximize o lucro líquido nas atividades agrícolas.

Por fim, num cenário de agricultura moderna, em que se deve primar pela máxima eficiência de utilização dos insumos, não faz sentido tratar os dejetos de animais como resíduos agropecuários. É mais racional considerá-los como subprodutos, os quais devem ser eficientemente reciclados dentro da cadeia produtiva. Assim, a reutilização dos resíduos orgânicos para a fertilização do solo deve ser tratada como necessidade básica dentro dos sistemas de produção. Contudo, sua utilização deve ser feita sob preceitos técnicos, já que é muito comum ocorrerem aplicações excessivas, as quais acarretam em poluição ambiental (Palhares, 2019). Nesse aspecto, este estudo trouxe avanços interessantes em relação a utilização dos resíduos compostados (composto orgânico) para finalidade de produção de matéria verde e seca, de definição de doses ideais e de parcelamentos de aplicação para a cultura da aveia, possibilitando a melhor escolha de dosagens e número de parcelamento com vistas ao aumento das produtividades de biomassa, com redução de custos e melhor aproveitamento dos resíduos agrícolas. Entretanto, mais estudos devem ser realizados com estes resíduos agrícolas nas mais diversas culturas cultivadas a fim de determinar as melhores dosagens, formas, número e época das aplicações para que seja possível uma melhor estratégia de tomada de decisão com base em resultados de campo que tragam benefícios aos agricultores e às áreas agrícolas, assim como foi possível observar com esse trabalho. 


\section{Conclusões}

Com base na resposta da aveia preta à soma dos dois cortes (acumulados) conclui-se que:

- O composto orgânico nas doses de 10 a $30 \mathrm{Mg} \mathrm{ha}^{-1}$ para matéria verde e nas doses 15 e $20 \mathrm{Mg} \mathrm{ha}^{-1}$ para matéria seca foi superior a adubação mineral, independente do parcelamento ou em aplicação única. Já a dose $25 \mathrm{Mg}^{-1}$ para a matéria seca, foi superior em aplicação única.

- Para as condições experimentais do presente estudo, a máxima eficiência técnica foi encontrada com as doses de 19,1 e 18,7 Mg ha-1, em aplicação única do composto orgânico, para obtenção de matéria verde e seca, respectivamente. Parcelando a aplicação do composto orgânico em duas vezes, a máxima eficiência técnica foi encontrada nas doses 22,9 e 22,7 $\mathrm{Mg} \mathrm{ha}^{-1}$ para matéria verde e seca, respectivamente.

\section{Agradecimentos}

Os autores agradecem a Cooperativa Tritícola Mista Campo Novo Ltda., pela área experimental e a Empresa Rico Entulhos pelo fornecimento do composto orgânico.

\section{Referências}

Aita, C.; Giacomini, S. J.; Pujol, S. B.; Nicoloso, R. S. \& Corrêa, J. C. (2014). Aproveitamento dos dejetos de suínos e bovinos como fertilizantes: impactos ambientais e estratégias de mitigação. In: Palhares, J. C. P. \& Gebler, L. (Org.). Gestão ambiental na agropecuária. Brasília, DF: Embrapa, $2,199-234$.

Araújo, F.F. de; Tiritan, C.S. \& Oliveira, T.R. de. (2009). Compostos orgânicos semicurados na adubação de pastagem degradada de Brachiaria decumbens. Revista Ciência Agronômica, Fortaleza - CE, 40(1), 1-6. http://www.ccarevista.ufc.br/seer/index.php/ccarevista/article/view/396

Barbosa, G. C.; Caviglione, J. H.; Andrade, D. S. \& Costa, A. (2009). Produção de massa seca de aveia branca em solo com aplicação de resíduos animais. Synergismus Scyentifica, Pato Branco - PR, 4(1). http://revistas.utfpr.edu.br/pb/index.php/SysScy/article/view/548

Bratti, F. C. (2013). Uso da Cama Aviária como Fertilizante Orgânico na Produção de Aveia Preta e Milho. 2013.70 folhas. Dissertação (Mestrado em Zootecnia) - Universidade Tecnológica Federal do Paraná. Dois Vizinhos.

Cardoso, R. E. (2019). Adubação de pastagem Brachiaria brizantha cv. marandú já implantada com diferentes fontes e doses de nitrogênio. 2019. 39f. Dissertação (Mestrado em Zootecnia) - Instituto Federal de Educação, Ciência e Tecnologia, Rio Verde - GO.

Castro, C. S.; Lobo, U. G. M.; Rodrigues, L. M.; Backes, C. \& Santos, A. J. M. (2016). Eficiência de utilização de adubação orgânica em forrageiras tropicais. Revista de Agricultura Neotropical, 3, (4), 48-54. https://doi.org/10.32404/rean.v3i4.1144

Carvalho, N. E.; Hidalgo, P. H.; Padilha, M. de S.; Lapere, T. E. L. \& Lourente, E. R. P. (2016). Produtividade de pastagem sob sistema orgânico. Cadernos de Agroecologia, 11(2), 1-8. https://revistas.aba-agroecologia.org.br/index.php/cad/article/view/21730

Costa, N. D. L.; Magalhães, J. A.; Townsend, C. R. \& Paulino, V. T. (2004). Fisiologia e manejo de plantas forrageiras. EMBRAPA Rondônia - Documentos (INFOTECA-E).

CQFS-RS/SC - Comissão de Química e Fertilidade do Solo - RS/SC. (2016). Manual de calagem e adubação para os Estados do Rio Grande do Sul e de Santa Catarina. Porto Alegre: SBCS-NRS, 376 p.

Coradini, L. G.; Röpke, L. B. Castihlo, J. O. P. \& Vieira, R. F. G. (2020). Simulação econômica de pastagens de inverno. Brazilian Journal of Animal and Environmental Research, 3(3), 2513-2543. 10.34188/bjaerv3n3-161

Edvan, R. L.; Santos, E. M.; Vasconcelos, W. A.; Souto Filho, L. T.; Borburema, J. B.; Medeiro, G. R. \& Andrade, A. P. (2010). Utilização de adubação orgânica em pastagem de capim-buffel (Cenchurus ciliares cv. Molopo). Archivos de Zootecnia, 59(288), 499-508. https://scielo.isciii.es/scielo.php?script=sci_arttext\&pid=S0004-05922010000400003

Ferraro, D. O.; Oesterheld, M. (2002). Effect of defoliation on grass growth: a quantitative review. Oikos, 98(1), 125-133. https://doi.org/10.1034/j.16000706.2002.980113.x

Ferreira, D. F. (2019). Sisvar: a computer analysis system to fixed effects split plot type designs. Revista Brasileira de Biometria, 37(4), 529-535. https://doi.org/10.28951/rbb.v37i4.450

Gonçalves, G. K.; Pozzebon, N. J.; Aguer, J. L. T.; Caleffi, H. V.; Sarturi, J. E. C.; Mendes, F.B.; Guedes, K. S.; Menezes, L. M. \& Katayama, R. (2017). Produtividade e qualidade nutricional da cultivar de azevém BRS ponteio submetido a diferentes tipos de adubação. Revista Científica Rural, 19(1), 70-87. file:///C:/Users/Eduardo\%20L.\%20de\%20Souza/Downloads/rcr_azevem.pdf

IBGE. (2021). Instituto Brasileiro de Geografia e Estatística. Estatística da Produção Pecuária Brasil, 50p. Disponível em: https://biblioteca.ibge.gov.br/visualizacao/periodicos/2380/epp_2021_2tri.pdf. Acesso em 23 de out 2021. 
Indicações Técnicas para a Cultura da C: XXXIV Reunião da Comissão Brasileira de Pesquisa de Aveia FUNDAÇÃO ABC. Passo Fundo: Ed: Universidade $\begin{array}{llll}\text { de } & \text { Fasso } & \text { Fundo, 2014, } & \text { 136p. }\end{array}$ https://www.bibliotecaagptea.org.br/agricultura/culturas_anuais/livros/INDICACOES\%20TECNICAS\%20PARA\%20A\%20CULTURA\%20DA\%20AVEIA.p df. Acesso em 27 de out 2021.

Köppen, W. (1931). Grundriss der Klimakunde: Outline of climate science. Berlin: Walter de Gruyter.

Liu, Z. G. \& Li, Z. Q. (2010). Effects of different grazing regimes on the morphological traits of Carex duriuscula on the Inner Mongolia steppe, China. New Zealand Journal of Agricultural Research, 53(1), 5-12. https://doi.org/10.1080/00288231003606047

Macêdo, A. J. S.; Edvan, R. L.; Santos, E. M \& Soares, M. N. (2018). Adubação orgânica em pastagens tropicais: Revisão. Revista eletrônica de Veterinária, 19(3). https://www.researchgate.net/publication/323431486_Adubacao_organica_em_pastagens_tropicais_Revisao

MALAVOLTA, E. (2006). Manual de nutrição mineral de plantas. São Paulo: Agronômica Ceres.

Mitchell Junior, C. C. (1991). The value and use of poultry waste as a fertilizer. In: Poultry by-product managment handbook. Alabama: Auburn University, Cooperative Extensive Service.

Oliveira, P.A.V. (1993). Manual de manejo e utilização dos dejetos de suínos. EMBRAPA-CNPSA. Documentos, 27,188 p.

Palhares, J. C. P. (2019). Produção animal e recursos hídricos: tecnologias para manejo de resíduos e uso eficiente dos insumos. Brasília, DF: Embrapa, 210 p.

Patzlaff, N. L; Zulpo, A. P. \& Rossi, D. S. (2020). A importância do uso da dose correta na adubação nitrogenada de tifton 85. Revista Científica Rural, 22(2). https://doi.org/10.30945/rcr-v22i2.3256

Pedrosa, T. D.; Farias, C. A. S.; Pereira, R.A. \& Farias, E.T.R. (2013). Monitoramento dos parâmetros físico-químicos na compostagem de resíduos agroindustriais. Nativa, 1(1), 44-48. 10.31413/nativa.v1i1.1335

Ramires, M. F.; Souza, E. L.; Fontanive, D. E.; Bianchetto, R.; Cezimbra, J. C. G. \& Antoniolli, Z. I. (2021). Uso potencial de resíduos de abatedouro de suínos como fonte de nutrientes na agricultura. Revista em Agronegócio e Meio Ambiente, 14(1). 10.17765/2176-9168.2021v14n1.e006413

Rocha Junior, P. R.; Andrade, F. V.; Mendonça, E. S.; Donagemma, G. K.; Fernandes, R. B. A.; Bhratharai, R. \& Kalita, P. K. (2016). Soil, water, and nutrient losses from management alternatives for degraded pasture in Brazilian Atlantic Rainforest biome. Science of the Total Environment, 583, 53-63, https://doi.org/10.1016/j.scitotenv.2016.12.187

Rosa, A. P. (2009). Avaliação da viabilidade técnica e ambiental do uso do conteúdo ruminal bovino como biocombustível. 2009. 90f. Dissertação (Mestrado em Saneamento Meio Ambiente e Recursos Hídricos) - Universidade Federal de Minas Gerais, Belo Horizonte.

Santos, H. G. dos; Jacomine, P. K. T.; Anjos, L. H. C. dos; Oliveira, V. A. de; Lumbreras, J. F.; Coelho, M. R.; Almeida, J. A. de; Araujo Filho, J. C. de; Oliveira, J. B. de \& Cunha, T. J. F. (2018). Sistema Brasileiro de Classificação de Solos. 5. ed. rev. e ampl. Brasília, DF: Embrapa, 356 p.

Schüller, E. M.; Gonçalves, G. K.; Nascimento, B. de O.; Birck, V.; Schüller, M.; Mendes, F. B.; Galarza, R. de M. \& Gambin, A. M. (2020). Influência do esterco bovino na produção e qualidade proteica da cultivar de azevém BRS ponteio. Brazilian Journal of Development, 6(1), 2685-2697. 10.34117/bjdv6n1194

Sileshi, G. W.; Nhamo, N.; Mafongoya, P. L. \& Tanimu, J. (2016). Stoichiometry of animal manure and implications for nutrient cycling and agriculture in subSaharan Africa. Nutrient Cycling in Agroecosystems, 107(1), 91-105. 10.1007/s10705-016-9817-7

Silva, L. H. X. (2017). Estratégias de adubação orgânica em pastagem de Brachiaria brizantha cv. Marandu com Stylosanthe spp no Bioma Cerrado. 2017. 232f. Tese (Doutorado em Zootecnia) - Escola de Veterinária e Zootecnia da Universidade Federal de Goiás. Goiânia.

Tedesco, M.J.; Volkweiss, S.J. \& Bohnen, H. (1995). Análise de solo, planta e outros materiais. 2.ed. Porto Alegre, Universidade Federal do Rio Grande do Sul, 174p.

Tiesdale, S. L.; Nelson, W. L. \& Beaton, J. D. (1993). Soil Fertility and fertilizers. 5.ed. New York: Macmillan.

Zanine, A. M. \& Ferreira, D. J. (2015). Animal Manure as a Nitrogen Source to Grass. American Journal of Plant Sciences, 6(7), 899-910. 10.4236/ajps.2015.67098 